\title{
HUBUNGAN ANTARA SPIRITUAL WELL BEING DENGAN COPING PADA MUSYRIF/AH MA'HAD SUNAN AMPEL AL- 'ALY (MSAA) UNIVERSITAS ISLAM NEGERI (UIN) MAULANA MALIK IBRAHIM MALANG
}

\author{
Devi Kurnia \\ Fakultas Psikologi \\ Universitas Islam Negeri (UIN)Maulana Malik Ibrahim Malang \\ Jl. Gajayana 50 Malang Telp. 0341-558916
}

\begin{abstract}
Abstrak -Sejahtera secara spiritual menjadi suatu kebutuhan bagi setiap manusia. Seseorang yang sejahtera secara spiritual tentu dapat menghadapi dan menyelesaikan segala persoalan kehidupan. Usaha menyelesaikan masalah ini dikenal dengan sebutan coping. Terdapat beberapa faktor yang berhubungan dengan Coping, salah satunya yaitu Spiritual Well Being (SPWB) atau kesejahteraan spiritual. Penelitian ini bertujuan untuk mengetahui apakah terdapat hubungan antara Spiritual Well Being (SPWB) dengan Coping pada Musyrifah.Populasi dalam penelitian ini adalah Musyrif/ah Ma'had Sunan Ampel Al-'Aly Universitas Islam Negeri Maulana Malik Ibrahim Malang. Pengambilan sampel dilakukan dengan menggunakan teknik random sampling dengan jumlah sampel yaitu 45 orang. Rancangan penelitian menggunakan penelitian kuantitatif korelasi dan pengambilan data menggunakan metode skala.Pada pengolahan data untuk menguji validitas menggunakan product moment correlation dari Pearson, dan reabilitas memakai Alpha cronbach. Pengolahan data tersebut diolah dengan bantuan program SPSS 16.0 for windows. Berdasarkan hasil analisis data, pada variabel Spiritual Well Being (SPWB) dari 45 sampel sebanyak 5 orang (11\%) memiliki tingkat Spiritual Well Being (SPWB) yang masuk pada kategori tinggi, 32 orang $(71 \%)$ berada pada kategori sedang, sedangkan sebanyak 8 orang $(18 \%)$ berada pada kategori rendah. Musyrif/ah yang menggunakan Problem Focused Coping memiliki prosentase $51 \%$,dengan jumlah 23 orang, dan 49\% (22 orang) menggunakan aspek emotion focused-Coping. Pada variabel Coping, dari 50 sampel sebanyak 5 orang (11\%) memiliki tingkat Copingpada kategori tinggi, sebanyak 31 orang $(69 \%)$ berada pada kategori sedang, sedangkan sebanyak 9 orang (20\%) masuk pada kategori rendah. kontribusi variabel Spiritual Well Being terhadap Coping yaitu sebesar 20,9\%. Variabel SPWB memiliki pengaruh kontribusi sebesar 10,8\% terhadap aspek PFC, dan 16,6\% terhadap aspek EFC. Berdasarkan analisis korelasional diperoleh $r$ hitung $=0,457$ sig 0,001 $<0,05$, maka terdapat hubungan yang positif antara Spiritual Well Being (SPWB) dengan Coping pada Musyrif/ah MSAA UIN Maliki Malang.
\end{abstract}

Kata Kunci: Spiritual Well Being, Coping

PSIKOISLAMIKA. Jurnal Psikologi Islam (JPI) copyright @ 2014 Laboratorium Penelitian, Kajian Psikologi Islam dan Penerbitan. Volume 11. Nomor 1, Tahun 2014 


\section{PENDAHULUAN}

Ma'had Sunan Ampel Al-Aly (MSAA) merupakan icon UIN Maliki Malang yang membedakannya dengan kampus lain, untuk mewujudkan integrasi agama dan ilmu umum, MSAA mengadopsi asrama yang bercirikan pesantren, kehidupan dan kegiatan yang ada didalamnya didesain layaknya pesantren pada umumnya. Peran Musyrif/ah sebagai pembina atau pengurus mahasantri sangat menentukan jalannya roda kehidupan di MSAA, model kerja yang diterapkan oleh Musyrif/ah tentu sangat berpengaruh. Sebagai orang yang bertanggungjawab akan kematangan beragama mahasantri, konsep Coping yang diterapkan oleh Musyrif/ah tidak jauh dari hal-hal yang berhubungan dengan spiritual atau religius. Seseorang ketika menghadapi suatu masalah dalam hidupnya selalu melakukan Coping, yaitu usaha yang dilakukan untuk mengatasi tekanan atau masalah, dapat didefinisikan pengertian Coping yaitu mencoba menjalani segala sesuatu sebagai resiko kehidupan, yang dapat dilakukan dengan mekanisme sabar, menahan diri, mengermbalikan segala permasalahan hanya pada Tuhan, senantiasa bersyukur, mudah memberi ma'af, dan adaptasiadjustment. Terdapat dua bentuk strategi Coping, yaitu : perilaku Coping yang berorientasi pada masalah (Problem Focused Coping-PFC) dan perilaku Coping yang berorientasi pada emosi (Emotion Focused Coping-EFC) yaitu strategi penanganan stress dimana individu memberikan respon terhadap situasi stress dengan cara emosional.

Kesejahteraan spiritual tidakakan serta merta didapat melainkan membutuhkan rangkaian proses. Orang yang sejahtera secara spiritual tentu cerdas secara spiritual. Spiritual Well Being akan memberikan ketentraman bagi tiap individu, yaitu sebuah perasaan bagaimana sesuatu berjalan sebagaimana mestinya. Orang yang memiliki dimensi spiritual yang kuat mempunyai kedamaian yang membuat mereka siap dalam menghadapi segala permasalahan dan cobaan.

\section{TINJAUAN PUSTAKA \\ Pengertian Spiritual Well Being}

Kesejahteraan spiritual adalah suatu kondisi dimana seseorang terpenuhi kebutuhan/ bahagia secara ruhani atau kejiwaannya.

\section{Spiritualitas dan Religiusitas}

Spiritualitas adalah kesadaran manusia tentang diri, asal, tujuan, dan nasib. Sedangkan Religiusitas (agama) merupakan kebenaran mutlak dari kehidupan yang memiliki manifestasi fisik di atas dunia

\section{Tingkatan Spiritualitas}

a. Nafs Ammarah (The Commanding Self)

Tahapan dimana orang yang nafsunya didominasi godaan yang senantiasa mengajak ke arah kejahatan.

b. Nafs Lawwamah (The Regretful Self)

Tahapan dimana manusia mulai memiliki kesadaran terhadap perilakunya, dapat membedakan yang baik dan yang benar, dan menyesali kesalahan-kesalahannya.Namun belum memiliki kemampuan untuk mengubah gaya hidupnya dengan cara yang signifikan.

c. Nafs Mulhimah (The Inspired Self)

Tahapan ketika seseorang mulai merasakan ketulusan dari ibadahnya. la benar-benar termotivasi pada cinta kasih, pengabdian dan nilai-nilai moral.

d. Nafs Muthma'innah (The Contented Self)

Pada tahap ini, orang merasakan kedamaian sehingga membuat seseorang lebih dekatdengan Tuhannya. Tingkat ini membuat seseorang menjadi berpikiran terbuka, bersyukur, dapat dipercaya, dan penuh kasih sayang, dapat dikatakan bahwa seseorang telah mencapai tingkat jiwa yang tenang.

e. Nafs Radhiyah (The Pleased Self)

Tahapan dimana seseorang tetap bahagia dalam keadaan sulit, musibah, atau cobaan dalam kehidupannya. Ia menyadari bahwa segala kesulitan datang dari Allah untuk memperkuat imannya.

f. Nafs Mardiyah (The Self Pleasing to God)

Pada tahap ini, seseorang telah menyadari bahwa segalanya tidak dapat terjadi begitu saja melainkan berasal dari Allah. Tidak ada lagi rasa takut dan tidak lagi meminta..

g. Nafs Safiyah (The Pure Self)

Titik ini merupakan titik kesucian, tidak ada nafs yang tersisa, hanya penyatuan dengan Allah.

\section{Aspek-AspekSpiritual Well Being}

1. Affiliation (afiliasi): Relate to God takes care of persons and one's experience of a positive relationship with God. Menjelaskanhubungan yang positifdenganTuhan

2. Alienation (pengasingan): relate to one's sense of dissatisfaction with life and to one's sense of distance from God. Menjelaskan tentang kebermaknaan, ketidakpuasan dengan hidup dan merasa ada jarak denganTuhan.

3. Satisfaction with life (kepuasanhidup): relate to one's sense of satisfaction with life. 
Menjelaskan hal-hal yang berhubungan dengan kepuasan serta masa depan

\section{Spiritual Well Being dalam Perspektif Islam}

Sejahtera dalam islam identik dengan kata bahagia, bahagia sendiri adalah terjemahan dari bahasa Arab "asssa'adah" yang berarti bahagia atau mujur Pengertian Coping

strategi atau pilihan cara berupa respon perilaku dan respon pikiran serta sikap yang digunakan dalam rangka memecahkan permasalahan yang ada agar dapat beradaptasi dalam situasi menekan

\section{Strategi Coping}

Strategi Coping merupakan suatu upaya individu untuk menanggulangi situasi stres yang menekan akibat masalah yang dihadapinya dengan cara melakukan perubahan kogntif maupun prilaku guna memperoleh rasa aman dalam dirinya sendiri.

\section{Sumber dan Fungsi Coping}

Sumber Coping yaitu: Materi (seperti makanan, uang); Fisik (seperti vitalitas dan kesehatan;Psikologis ( seperti kemampuan problem solving); Social (seperti kemampuan interpersonal, dukungan social); danSpiritual (seperti perasaan kedekatan dengan Tuhan) Fungsi coping yaitu: Mengurangi kondisi lingkungan yang membahayakan, mempertinggi kemungkinan kesembuhan, mentoleransi atau mengakui peristiwa-peristiwa dan kenyataankenyataan yang negative, memelihara self-image yang positif, memelihara keseimbangan emosi, melestarikan hubungan baik dengan orang lain

\section{Bentuk-Bentuk Coping}

a. Problem-focused Coping(PFC)

Problem-focused Coping, yaitu usaha mengatasi stress dengan cara mengatur atau mengubah masalah yang dihadapi dan lingkungan sekitarnya yang menyebabkan terjadinya tekanan. Aspek PFC yaitu:

1. Instrumental Action (tindakan secara langsung)

Usaha yang dilakukan Individu dengan cara menetapkan langkah-langkah yang mengarah pada penyelesaian masalah secara langsung, fokus pada masalah yang menjadi sasaran dan menyusun rencana bertindak kemudian melaksanakannya

2. Cautiousness (kehati-hatian) Individu melakukan usaha dengan cara berfikir, meninjau, dan mempertimbangkan beberapa alternatif pemecahan masalah,

3. Negotiation (Negoisasi)

Usaha yang ditujukan pada orang lain yang terlibat atau yang menjadi penyebab masalah yang sudah dihadapinya untuk ikut serta memikirkan atau menyelesaikan masalahnya

b. Emotion-focused Coping (EFC)

Emotion-focused Coping, yaitu usaha mengatasi stress dengan cara mengatur respon emosional dalam rangka menyesuaikan diri dengan dampak yang akan ditimbulkan oleh suatu kondisi atau situasi yang dianggap penuh tekanan. Indikator yang berorientasipadastrategiiniantaralain:

1. Escapism (pelarian diri dari masalah) Individu melakukan usaha dengan cara berkhayal atau membayangkan hasil yang akan terjadi atau mengkhayalkan seandainya ia berada dalam situasi yang lebih baik dari situasi yang dialaminya sekarang.

2. Minimization (meringankan beban masalah) Usaha yang dilakukan individu dengan menolak memikirkan masalah (denial) dan menganggapnya seakan-akan masalah tersebut tidak ada

3. Self blame (menyalahkan diri sendiri) Perasaan menyesal, menghukum dan menyalahkan diri sendiri atas tekanan masalah yang terjadi.

4. Seeking meaning (mencari arti) Cara individu mengatasi stress dengan mencari makna atau hikmah dari kegagalan yang dialaminya.

\section{METODE PENELITIAN}

Populasi dalam penelitian ini adalah musyrif dan musyrifah Ma'had Sunan Ampel Al-Aly UIN Maliki Malang yang berjumlah 222 orang.peneliti mengambil sampel $20 \%$ dari populasi yaitu 45 subyek. Pengambilan sampelnya dilakukan dengan menggunakan teknik simple random sampling.Metode pengumpulan data yang digunakan dalam penelitian ini adalah metode skala. Adapun skala yang akan digunakan dalam penelitian ini berjumlah dua buah, yaitu skala Spiritual Well Being dan skala Coping. Skala Spiritual Well Being berjumlah 20 aitem, Skala Coping berjumlah 34 aitem. Metode analisis data yang digunakan adalah metode analisis normatif, analisis prosentase dan analisa korelasi Product Moment menggunakan program komputerSPSS 16.0 for windows. 
HASIL

Berdasarkan hasil analisis uji korelasi Product Moment antara Spiritual Well Being dengan Coping pada Musyrif/ah MSAAUIN Maliki Malang menunjukkan $r=0,457$ dengan $\mathrm{Sig}=0,005$. Hal ini menujukkan bahwa terdapat hubungan yang signifikan positif antara Spiritual Well Being dengan Coping.Dapat dijelaskan bahwa $\mathrm{rxy}=0,457$; $\mathrm{Sig}=0,005$; < 0,05 . Itu artinya hipotesis yang diajukan terbukti kebenarannya. Sedangkan kontribusi variabel Spiritual Well Being terhadap Coping yaitu sebesar $20,9 \%$, jadi $79,1 \%$ dipengaruhi oleh aspek lain diluar Spiritual Well Being, bisa jadi aspek lain tersebut meliputi usia, tingkat pendidikan, lingkungan sosial dan sebagainya.

Hasil pengolahan data penelitian menunjukkan bahwa ada hubungan positif yang signifikan antara Spiritual Well Beingdengan Copingpada Musyrif/ah MSAA UIN Maliki Malang ( $r x y=0,457, p<0,05$ ). Hasil penelitian ini sesuai dengan hipotesis yang diajukan peneliti, yaitu terdapat hubungan positif antara Spiritual Well Being dengan Coping pada Musyrif/ah MSAA UIN Maliki Malang. Dimana mayoritas dari 45 sampel Musyrif/ah MSAAUIN Maliki Malang memiliki tingkat Spiritual Well Being dan tingkat Coping pada kategori sedang. Hubungan yang signifikan ini dapat diartikan bahwa antara Spiritual Well Being dengan Coping pada Musyrif/ah MSAA UIN Maliki Malang memiliki korelasi antar variabelnya. Sedangkan jika ditinjau dari masing-masing aspek, hasil korelasi SPWB dan aspek PFC menunjukkan $r$ $=0,329$ dengan $\mathrm{Sig}=0,005$, hal ini menunjukkan bahwa ada hubungan antara keduanya, dimana hubungan itu diartikan dengan hubungan yang Signifikan positif, sedangkan hasil korelasi SPWB dan aspek EFC menunjukkan $r=0,407$ dengan Sig $=0,005$, hal ini menunjukkan bahwa ada hubungan antara keduanya, dimana hubungan itu diartikan dengan hubungan yang Signifikan positif. Hal ini memberi kesimpulan bahwa semakin tinggi tingkat SPWB akan semakin tinggi pula tigkat PFC maupun EFC.

Berdasarkan analisis regresi diperoleh hasil bahwa variabel SPWB memiliki pengaruh kontribusi sebesar $10,8 \%$ terhadap aspek PFC dan 89,2\% lainnya dipengaruhi oleh faktor-faktor lain diluar aspek PFC, sedangkan variabel SPWB memiliki pengaruh kontribusi sebesar $16,6 \%$ terhadap aspek EFC dan 83,4\% lainnya dipengaruhi oleh faktor-faktor lain diluar aspek EFC. Dari data tersebut terlihat bahwa aspek yang paling banyak disumbang oleh Spiritual Well Being adalah emotion focused-Coping. Hal ini dikarenakan dalam salah satu indikator emotion focused-Coping terdapat aspek seeking meaning yang berarti mencari makna atau hikmah dari kegagalan, hal ini berhubungan erat dengan spiritual.

Secara keseluruhan, kontribusi variabel Spiritual Well Being terhadap Coping yaitu sebesar $20,9 \%$, jadi $79,1 \%$ dipengaruhi oleh aspek lain diluar Spiritual Well Being, bisa jadi aspek lain tersebut meliputi materi, fisik, usia, tingkat pendidikan, lingkungan sosial dan sebagainya.

Menurut Pergament terdapat beberapa hal yang menjadi sumber Coping yang meliputi hal-hal yang memiliki pengaruh terhadap pemilihan seseorang atas strategi Coping tertentu., salah satunya adalah spiritual, yaitu perasaan kedekatan dengan Tuhan. Spiritual ini menjadi salah satu factor yang berpengaruh karena manusia selalu tidak terlepas dari kehidupan spiritual.

Penelitian ini sejalan dengan penelitian terdahulu dari Thesis Moodley yang membahaspenelitian yang berjudulThe Relationship Between Coping And Spiritual Well-Being In A Group Of South African Adolescents dengansubjek yang berjumlah 1283 remajaAfrikaduduk di SekolahMenengahAtas di Cape Town Afrika Selatan menemukanbahwaadahubunganpositif yang signifikanantaraCopingdanspiritual well being. Dalam penelitian ini juga ditemukan hubungan yang positif signifikan antaraCopingdanspiritual well being.

Hasil penelitian ini juga mendukung penelitian sebelumnya yang dilakukan oleh Hadisuprapto mengemukakan bahwa peningkatan pemahaman keagamaan pada diri seseorang akan mempengaruhi strategi seseorang dalam menghadapi masalahnya. Hasil penelitian yang dilakukan oleh Zalfa juga menunjukkan bahwa religiusitas merupakan salah satu faktor yang menjadi sumber Coping. Faktorfaktornya adalah materi, fisik, psikologis, sosial dan spiritual. Penelitian yang dilakukan oleh Emma Indirawati tentang Hubungan Antara Kematangan Beragamadengan Kecenderungan Strategi Copingpada Mahasiswa juga menunjukkan bahwa ada korelasi atau hubungan positif antara kematangan beragama dengan kecenderungan strategi Coping yaitu Problem focused Coping pada Mahasiswa. Hasil penelitian ini juga mendukung penelitian yang dilakukan Stone dan bahwa saat tingkah laku coping seharihari itu diukur, ditemukan delapan strategi coping yang biasa digunakan, termasuk religi (agama) adalah salah satunya yang bisa dijadikan acuan copingsehari-hari.

Darajat menyatakanbahwa keyakinan beragama menjadi bagian integral dari kepribadian seseorang. 
Keyakinan itu mengawasi segala tindakan, perkataan, bahkan perasaannya. Pada saat seseorang terbentur pada suatu permasalahan, maka keimanannya akan cepat bertindak menimbang dan meneliti dan mencari tahu bagaimana ajaran agamanya mengatur atau memberikan solusi terhadap permasalahan tersebut.

Kajian hubungan dua variabel tersebut tidak dibahas dalam islam, akan tetapi Al-Qur'an telah membahas hal tersebut. Dalam beberapa dalil disebutkan tentang Copingdan kesejahteraan spiritual. Seperti pada ayat berikut:

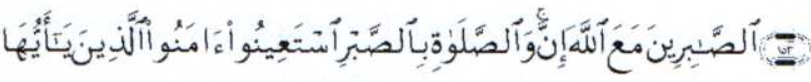

Hai orang-orang yang beriman, Jadikanlah sabar dan shalat sebagai penolongmu[99], Sesungguhnya Allah beserta orang-orang yang sabar. (QS. AlBaqarah:153)

\section{DAFTAR PUSTAKA}

Blonna, Richard. 2005. Coping with Stress In a Changing World. New York: McGraw-Hill

Darajat Z. 1991. limit/iwa Agama (Cetakan Ketiga belas). Jakarta: PT. KaryaUnipress

Davidson, Gerald,dkk. 2006. Psikologi Abnormal (terjemahan). Jakarta: Rajawali Pers

Ellison,C.W, Spiritual Well Being: Conceptualization and Measurement, Journal of Psychology and Theology, vol 11

Graham, dkk,. 2001. Religion And Spirituality In Coping With StressJournal of Counseling and Values 46

GuidedbookofMa'hadSunanAmpel Al-Ali the State Islamic University of Malang 2006-2007

Hasan, Aliah B. 2006. Psikologi Perkembangan Islami. Jakarta: PT Rajagrafindo Persada

Hasan, Aliah B. 2008. Pengantar Psikologi Kesehatan Islami. Jakarta: PT Rajagrafindo Persada

Indirawati, Emma.Hubungan antara Kematangan Beragama dengan Kecenderungan Strategi Coping, jurnal Psikologi Universitas Diponegoro Vol 3 no 2, Desember 2006

Jalaludin. 2012. Psikologi Agama. Jakarta: Rajawali Pers

Lazarus, R.S and Folkman. 1984. Stress, Appraisal and Coping. New York: Springer

Miller, G., Fleming, W., \& BrownAnderson, F. (1998). Spiritual Well-Being Scale: Ethnic differences
Ayat diatas menjelaskan bagaimana seseorang seharusnya dalam menghadapi segala situasi, termasuk apabila mendapat masalah. Allah menganjurkan untuk bersabar dan bertawakal (dengan shalat). Kedua hal ini merupakan salah satu bentuk Coping. Apabila hal ini mereka terapkan maka Allah selalu bersama mereka. Hal ini dapat diartikan jika Allah selalu bersama kita maka jiwa akan tenteram dan kesejahteraan spiritual dapat kita rasakan.

\section{KESIMPULAN}

Ada hubungan positif antara Spiritual Well Being dengan Coping pada Musyrif/ah MSAA UIN Maliki Malang. Adanya hubungan positif tersebut menunjukkan bahwa hipotesis yang menyatakan ada hubungan positif antara Spiritual Well Being dengan Coping pada Musyrif/ah MSAA UIN Maliki Malang diterima. Hubungan yang terjadi adalah hubungan yang timbal balik, yaitu saling berpengaruh satu sama lain.

between Caucasians and African-Americans. Journal of Psychology and Theology, 26,358-364.

Moodley, Trevor. 2008. Thesis The Relationship Between Coping And Spiritual Well-Being During Adolescence. University Of The Free State :Bloemfontein

Nawawi, Rif atSyauqi.2011.KepribadianQur'ani, Jakarta: Amzah

Pergament. 1997.The Psychology of Religion and Coping: Theory, Research, Practice, New York: Guilford Press

Smet.1994. Psikologi Kesehatan.Jakarta: Grasindo

Stone, A. A. and Neale, J. M. 1984. New Measure of Daily Coping: Development and Preliminary Result. Journal of Personality and Social Psychology. Vol. 46 (4)

Taylor, Shelley E. 2006. Health Psychology 6th ed, New York: Mc.Graw-Hill

Utsey, Shawn O, et al,.2007. Spiritual WellBeing As A Mediator Of The Relation Between Culture-Specific Coping And Quality OfLife In A Community Sample Of African Americans, Journal of Cross-Culture Psychology vol. 38 no 2

Zalfa, K. 2009. Sripsi: Hubungan antara Religiusitas dengan Strategi Coping pada Santri Pondok Pesantren Nurul Huda Mergosono Malang. Malang: UIN 